\title{
Trial, Error, and Breakthrough: A Review of HIV Vaccine Development
}

Sheila M Barry*, Alfredo J Mena Lora and Richard M Novak

Division of Infectious Diseases, Immunology and International Medicine, Department of Medicine, College of Medicine, University of Illinois at Chicago, Chicago, Illinois, USA

\begin{abstract}
With more than 35 million infected in over thirty years, the HIV pandemic has been a unique challenge to the scientific community. The development of effective anti-retroviral therapy has decreased morbidity and mortality of those infected with HIV, but a comprehensive approach that includes effective prevention strategies will be needed to curb this unique pandemic. Vaccines remain the best option, but the development of a safe and effective preventive HIV vaccine has defied decades of research. Over 30 products have been tested in more than 85 trials, but no safe and effective vaccine has been developed yet. Despite these setbacks, these decades of research have broadened the understanding of HIV immunopathogenesis and closer to the goal of a successful HIV vaccine. In 2009, a primeboost vaccine demonstrated an efficacy of $31.2 \%$. This trial, RV144, signaled hope for the future and served as proof of concept that an effective HIV-1 vaccine is possible. Understanding the unique obstacles in HIV vaccine development has been key in creating breakthroughs and tracing a path forward. The complexity of this challenge has required innovative approaches to vaccine development. Future HIV preventive vaccine candidates may target multiple immune pathways. Strategies such as cytotoxic vaccines, envelope targets and antibodies such as broadly neutralizing antibodies or monoclonal antibodies may work in concert to achieve protection from HIV acquisition. An effective HIV preventive vaccine is ever near.
\end{abstract}

Keywords: HIV; Vaccine; Viral vectors; Neutralizing antibodies; Clinical trials

\section{Introduction}

The human immunodeficiency virus (HIV) pandemic is now in its fourth decade. The WHO estimates that over 35.3 million people are living with HIV worldwide. With over 1.6 million deaths and 1.6 million infected in 2012, the HIV epidemic continues to be a major scientific challenge [1]. Many roadblocks have been overcome. The development of effective anti-retroviral therapy (ARV) has had a dramatic effect in the quality of life of those living with HIV and has curbed mortality. The large-scale implementation of anti-retroviral therapy in the developing world has had a major impact on the disease burden where it is needed most $[2,3]$. Of the estimated 6,300 new infections per day, 95\% occur in low-middle income countries. Though worldwide ARV coverage is at $55 \%$, in certain low income areas of Africa coverage remains low at $16-35 \%$ [1]. The daunting number of new infections and the percentage of those without access to ARVs highlights the need for effective prevention strategies. Three decades later, vaccines remain the best hope, but the development of a safe and effective preventive HIV vaccine remains elusive.

Since HIV was first identified in 1983 as the cause of AIDS, the scientific community has been relentlessly searching for a HIV vaccine. That year, the Secretary of Health and Human Services declared that a vaccine would be available within two years [4]. This first prediction was both hopeful and naive. Researchers failed to recognize the complexities of HIV virology, the intricate relationship between HIV and the immune system, and the gaps in scientific knowledge necessary to resolve for vaccine development. Three decades of research have produced over 30 products which have been tested in over 85 trials, but no safe and effective vaccine has been found thus far [5,6]. Though this record may seem daunting or discouraging, these studies have broadened the understanding of HIV-1 and have brought the scientific community closer to the goal. Hope was further re-invigorated in 2009 when the results of the RV144 trial were published. This study was unique, with a prime-boost vaccine that had an efficacy of $31.2 \%$

[7]. The modest protection shown in the RV144 trial was more than encouraging; it served as proof of concept that an effective HIV-1 vaccine is indeed possible. With more understanding of the many obstacles in place towards an HIV vaccine, the scientific community is more confident than ever that this problem can be solved and will continue to move forward.

\section{Understanding the Obstacles}

The challenges in the development of a prophylactic HIV-1 vaccine are many and are unprecedented in the history of medicine (Table 1). First and foremost are the biologic properties of HIV-1 itself, a retrovirus with broad genetic variation and worldwide viral diversity. The complex interaction between HIV-1 and the human immune system and the subsequent inability of the immune response to clear

\section{Viral factors}

- Extensive viral clade and sequence diversity

- Early establishment of latent viral reservoirs

- Viral evasion of humoral and cellular immune responses

- Immune correlates of protection unclear

- Antibody responses typically type-specific

\section{Research limitations}

- No method yet exists to elicit broadly reactive NAbs

- Limited interest from the pharmaceutical industry

- Funding Challenges

Table 1: Challenges in the Development of a preventive HIV-1 Vaccine.

*Corresponding author: Sheila M Barry, University of Illinois at Chicago College of Medicine, Division of Infectious Diseases, Immunology and International Medicine, 808 S. Wood Street. Room 888, M/C 735, Chicago, Illinois 60612 USA, Tel: 312-996-0995; Fax: 312-413-1657; E-mail: sbarry1@uic.edu

Received July 17, 2014; Accepted September 28, 2014; Published October 07 2014

Citation: Barry SM, Mena Lora AJ, Novak RM (2014) Trial, Error, and Breakthrough: A Review of HIV Vaccine Development. J AIDS Clin Res 5: 359. doi:10.4172/2155 6113.1000359

Copyright: ( 2014 Barry SM, et al. This is an open-access article distributed unde the terms of the Creative Commons Attribution License, which permits unrestricted use, distribution, and reproduction in any medium, provided the original author and source are credited. 
the infection is another major obstacle as well. Researchers have been limited by the lack of an ideal animal model. The current animal model is imperfect and does not translate smoothly to human infection. Despite recent breakthroughs, funding has stagnated, decreasing the capacity to conduct research.

Before expanding on these obstacles, one must understand key interactions between HIV-1 and the immune system. Once infected with HIV, a burst of viremia occurs [8]. Latently infected, resting $\mathrm{CD} 4+\mathrm{T}$ cells are established early during primary infection. HIV-1 specific CD8+ and CD4+ T cells are created as a consequence of this initial viremia, and HIV-1 viral load subsequently declines via CD8+ T-cell mediated responses [9]. Antibodies appear between weeks 6 to 12 . However, the virus is able to escape recognition due to genetic changes in the viral envelope. As the virus escapes both the humoral and cell-mediated immune responses, the viral load increases and damage to the immune system progresses [10]. Though long-term non-progressors and elite controllers have been identified, no human has been able to clear HIV-1 infection without intervention [11]. Even with potent ARVs and undetectable HIV-1 levels in the blood, HIV1 persists in reservoirs within multiple organ systems, including the reticuloendothelial system and is never fully eradicated [12]. Thus, once infection is established, the high replication and mutation rates present insurmountable obstacles to the immune system as it attempts to clear the infection.

The broad diversity of HIV-1, with multiple subtypes, mutations, and groups, poses a great challenge towards vaccine development. Constant mutations have caused a variety of different groups and clades. Vaccines would need to effectively protect against this broad viral diversity and protect against infection by all clades. However, these clades differ by about $25-35 \%$ in env sequence and approximately $15 \%$ in gag sequence [5]. Since the discovery of the virus in 1983 , extensive research on the genome and structure of HIV has improved understanding of HIV immunopathogenesis [13]. The broad genetic diversity of the virus is a major challenge for the immune system and for the scientific community. Each virion contains two copies of the single stranded RNA genome within its envelope [14,15]. This allows for recombination and creation of another level of diversity. The recombinant progeny are considered circulating recombinant forms if isolated in multiple people with no direct epidemiologic linkage. Otherwise, they are considered unique recombinant forms [15]. These differences contribute to the complexity and difficulty in development of a broadly active HIV vaccine. The inability of the immune system to naturally clear HIV-1 poses a major roadblock and until recently, no immune correlates of protection in humans existed. The classic paradigm for creating vaccines via subunits of the viral envelope have not provided a safe and effective vaccine despite dozens of trials on envelope peptides $[8,16]$. HIV envelope proteins gp120 and gp41 are necessary for binding and fusion with the host cell membrane. These proteins would be ideal targets for vaccine design. However, conserved viral epitopes that are exposed on monomeric envelope proteins become hidden within the envelope trimer, only becoming accessible during the very rapid fusion process. Envelope proteins are so heavily glycosylated that neutralizing antibodies have to overcome significant steric hindrance to be effective [10]. There are variable regions on the surface of gp120 that would be key targets for antibody production, but said antibodies have low immunogenicity and limited breadth, making them ineffective from a vaccine perspective [17].

Another major effort in HIV vaccine development is the use ofanimal models. Non-human primate (NHP) models challenged with simian immunodeficiency virus (SIV) and simian-human immunodeficiency virus (SHIV) have been used to study possible vaccine targets [18]. The SIVs are retroviruses found in non-human primates $[19,20]$. When SIV infects species other than their natural hosts, such as the SIV of sooty mangabeys infection of rhesus macaques, simian acquired immunodeficiency syndrome develops [19,21]. Parts of the HIV and SIV genomes have been combined to create chimeric viruses known as SHIV. This model has been instrumental for the study of HIV vaccines. Though NHPs and simian viruses have vast similarities between humans and HIV, small differences have big consequences. Thus, many vaccine targets and strategies that are found to be effective in NHPs have failed in humans [18]. The impact of inter-species differences poses a major challenge in the applicability of these models to humans. Though studies of NHPs and SIV/SHIV have brought forth significant contributions, they have failed to reliably predict human responses and remainonly a tool with limited ability to inform vaccine development.

Finally, decreased funding has reached HIV vaccine research as well and has posed a challenge in recent years. Funding for HIV vaccines decreased by 100 million in 2008 [22,23]. This was the first decrease in over three decades of research. Since then, funding has remained stagnant. Researchers worldwide responded with attempts to increase efficiency by forming collaborations to better utilize the collective knowledge and research infrastructure of organizations and institutions globally. At 847 million US dollars in 2012, funding for HIV vaccines is by no means insignificant, but neither is the research task at hand $[22,23]$. The trend towards decreased funding is discouraging and further decreases will without a doubt have a negative effect in vaccine research endeavors.

\section{Goals of a Successful Vaccine}

The primary aim of HIV vaccines is to prevent infection. After the failure of early vaccine studies, some researchers altered their aim to create "therapeutic vaccines" that would control established disease or alter disease progression in previously HIV-1 infected individuals. In order to achieve either aim, a successful vaccine must trigger appropriate responses from the host immune system. The traditional strategy in vaccine development has been to trigger expression of broadly neutralizing antibodies. There are instances when humoral immunity is not sufficient, and cell-mediated responses are necessary to control infection. Cytotoxic T cells limit the spread of HIV by killing infected cells, either through targeted killing pathways or by triggering apoptosis via secretion of granzymes and perforin [24,25]. In the case of HIV, a successful vaccine is one that would ideally be able to recruit both arms of the immune system to achieve its primary aim.

\section{Types of Vaccines}

Researchers have tried multiple different types of HIV vaccines with varying success. A live, attenuated virus was one of the earliest HIV vaccines attempted. This method, which was successful for multiple other viruses, including measles, rubella, and polio, involves altering the viral genome in order to decrease its pathogenicity. In the case of HIV, mutant viral strains that deleted multiple base pairs in the regulatory protein nef were studied in SIV animal models. At first, these viruses seemed to induce protective immunity against challenge with wild-type, pathogenic SIV 2.5 years after immunization; neutralizing antibody titers were very high at infection, no animals developed antigenemia and all maintained very low viral loads [26]. The perceived success of this virus was short-lived as other strains, built in similar manner, were pathogenic in adult and neonatal macaques and eventually progressed to AIDS [27]. In another experiment, monkeys 
were vaccinated with a SIV strain that contained a 12 base-pair deletion of nef. Surprisingly, several of these monkeys developed elevated viral loads and disease progression. Further analysis revealed the original nef deletion had mutated to repair the inframe deletion and revert back to the parental strain, thereby explaining the pathogenicity of the vaccine and underscoring the danger of using a live-attenuated vaccine $[28,29]$. Similar findings are mirrored in the history of individuals who were naturally infected with nef deleted HIV strains [30]. These individuals were asymptomatic for several years after acquiring HIV infection, but ultimately the original donor of blood products and 3 out of the 6 recipients developed late-onset immunosuppression and opportunistic infections consistent with AIDS [29-31] Taken together, these findings questioned the safety and efficacy of a live-attenuated HIV virus and no further work was performed.

Heat-inactivated or killed whole vaccines are very useful when the parameters of immunity are ill defined, as in the case of HIV. The best example of a successful killed whole virus vaccine is Jonas Salk's polio vaccine [32], but this vaccine is haunted by the potential to cause active infection through immunizing with incompletely inactivated virus [33]. Still, a whole killed virus was created and tested in individuals already infected with HIV as a method to slow disease progression. The vaccine, called Remune, is killed and depleted of surface envelope expression. It showed promise in early human studies as it was shown to increase immune responses, but effects on surrogate markers and viral DNA were inconsistent. A multicenter double-blind randomized controlled trial investigated the utility of combining Remune with anti-retroviral therapy and did not observe any effect on disease-free survival [34]. Remune continued to be investigated as an adjunctive therapy in therapeutic vaccination models. While no difference was seen in viral load set point, viral load rebound was slightly delayed in vaccinated individuals [35]. Recently, Immune Response BioPharma, who manufactures Remune, announced they are submitting a biologic license application to the FDA as a first step to bringing the vaccine to market [36]. It will be interesting to see what the future holds for this vaccine.

Additional vaccine types either present specific target viral proteins (e.g. recombinant gp120 envelope), encode plasmid DNA to elicit antigenic responses, or utilize other viruses as vectors to deliver target viral genes to immune cells. Each of these methods has had varying degrees of success and has been used, either alone or in combination, in human vaccine trials.

\section{Clinical Trials}

Multiple studies have explored the use of vaccines against HIV1 envelope proteins gp160 and gp120. These studies followed a "traditional" strategy to trigger expression of broadly neutralizing antibodies. Phase I studies were completed to examine the safety and immunogenicity of viruses in "low risk" populations. These studies showed the vaccines were well tolerated and induced high rates of binding antibodies after just 3 doses [37-39]. However, these responses were mainly type-specific against the homologous, tissue-culture derived virus and were not protective against primary isolates $[40,41]$. The AIDS Vaccine Evaluation group (AVEG) then further explored the utility of such vaccines in a phase II double-blinded, adjuvantcontrolled trial with two gp120 vaccines designed against X4-tropic clade B viruses [42]. After three doses of vaccine, $87 \%$ of study subjects developed neutralizing antibodies that persisted in $59 \%$ of subjects after 2 years. Notably, lower antibody responses were seen in IV drug users and heterosexual partners of HIV (+) individuals [42]. Despite being proven as safe vaccines, these phase I trials revealed antibody responses were too specific to the particular HIV strain and were inadequate to neutralize primary HIV isolates.

These earlier studies laid the groundwork for two large phase III trials. AIDSVAX B/B vaccine was a bivalent recombinant gp 120 vaccine against two clade $\mathrm{B}$ isolates; $\mathrm{MN}$, a tissue culture derived strain; and GNE-8, a primary isolate. VAX 004 was a randomized, double blind study that examined whether this vaccine could protect those at risk for sexual acquisition of HIV. The hypothesis was that antibodies against gp120 would bind, neutralize and eliminate HIV virions before infection occurred. Over 5000 men and 300 women were enrolled in the study. After 3 years, the rate of HIV infection was $6.7 \%$ in the vaccinated group and $7 \%$ in the unvaccinated group $[43,44]$. VAX 003 was a similar study utilizing AIDSVAX B/E, a vaccine with gp120 derived from a clade B isolate (MN) and a primary clade E isolate (CM244), and examined HIV acquisition in IV drug users in Thailand [45]. As before, the rate of HIV infection was similar in vaccinated and unvaccinated groups. Additionally, HIV (+) persons who received the vaccine did not demonstrate any differences regarding viral loads, CD4 counts or time to disease progression. These studies showed an envelope only vaccine was not efficacious to prevent HIV infection in these high-risk populations. The failure of these trials resulted in a paradigm shift in vaccine development, focusing the research effort primarily on vaccines that could induce cell-mediated immune responses as opposed to humoral responses.

DNA vaccines encode plasmids that do not integrate into the host cell genome, but rather remain episomal and act as expression vectors for antigenic viral proteins to induce cellular immunity [5]. AVEG and the NIH Vaccine Research Center (VRC) both created DNA vaccines that express HIV structural proteins from multiple different viral clades $[46,47]$. While these vaccines elicited substantial responses in mice and non-human primates, they were poorly immunogenic in humans unless they were administered with an Adenoviral vector boost $[46,48,49]$.

Considerable research has focused on live viral vectors as a method for antigen presentation in order to induce humoral immunity and HIV-1-specific CD8+ T lymphocyte responses. The most well studied viral vectors include poxviruses, specifically vaccinia and canarypox, as well as adenovirus.

Vaccinia vectors were studied very early on in vaccine development. $\mathrm{Hu}$, et al. first described insertion and expression of HIV envelope protein from a vaccinia vector in 1986 [50]. Since then, vaccinia vectors have been created that express HIV env, gag, and pol genes. Although they did induce antibody and $\mathrm{T}$ cell responses in animal models, such findings were not replicated in human subjects and the vaccine did not protect NHPs against HIV infection [51,52]. Additionally, vaccinia vectors have the potential to cause serious illness in immunocompromised individuals and skin reactions in persons with eczema. Therefore, other attenuated vaccinia strains were developed, namely the Modified Vaccinia Ankara (MVA) and the NYVAC (vP2010) viral strains. Both vectors have good safety profiles and have been shown to elicit immune responses in phase 1 testing [53-56]. However, immunogenicity was enhanced in subjects who were "primed" with a DNA vaccine prior to receiving the vaccinia virus "boost."

While vaccinia vectors continue in development, most attention had been diverted to adenovirus and canarypox vectors and the three large phase IIb trials that utilized each viral vector, namely the STEP vaccine trial, the HVTN 505 trial and the RV144 trial. 


\section{Dark Days: Adenovirus and the STEP Trial}

Adenoviral vectors are strains that have been made replication defective by mutations and deletions of the adenoviral genome. HIV constructs are then inserted in place of the deleted adenovirus genes and an exogenous promoter controls their expression. There are two main adenoviral vectors. The NIH Vaccine Research Center (VRC) vector (serogroup 5, Ad5) expresses HIV gag and pol from clade B and env from clades A, B, and C; while the Merck MRKAd5 vector is a compilation of 3 adenoviruses that express $g a g$, pol, and nef from clade B alone [6]. Both vaccines were able to induce humoral and cell mediated responses in animal models that could be enhanced by priming with DNA vaccines. However, they were unable to prevent infection. Instead, they modulated disease progression in animals. Vaccinated macaques had lower viral loads and did not progress into AIDS during study follow-up [57,58].

In 2003, researchers began human trials to evaluate the immunogenicity and efficacy of the MRKAd5 HIV-1 vaccine. The vaccine was found to be safe and capable of inducing $\mathrm{T}$ cell responses in a phase 1 trial [59]. As expected, study subjects with pre-existing immunity to Ad5 had attenuated responses, but this effect was partially overcome by higher doses of vaccine. With this promising result, a phase IIb study was launched in late 2004 .

The STEP study was a test-of-concept study that enrolled 3000 HIV-seronegative participants from the Americas, Australia and the Caribbean and randomized them to receive either three doses of MRKAd5 HIV-1 vaccine or placebo [60]. The goal was to demonstrate either decreased rates of infection or HIV viral load in vaccinated individuals. As seen in the phase I trial, the vaccine induced cellmediated responses in study subjects. Surprisingly, this was not sufficient to prevent infection. In fact, HIV infection and viral loads were either no different or higher in vaccinated subjects as compared to placebo controls. Subset analysis suggested that subjects with prior adenovirus immunity and/or who were uncircumcised were at highest risk for HIV-1 acquisition. A data-safety monitoring board concluded the study early due to evidence of vaccine futility at interim analysis. A parallel study, the Phambili study, examining the MRKAd5 HIV-1 vaccine in South Africa, where clade $\mathrm{C}$ is predominant, was stopped during enrollment due to the results of the STEP study and the 800 persons already vaccinated were followed. Initial analysis showed a higher rate of HIV infections in the vaccinated group, but it was not considered to be statistically significant [61]. However, a recent longterm follow-up of the Phambili study participants found a higher incidence of HIV-1 in vaccinated study subjects that was statistically significant and independent of number of vaccinations received, gender, circumcision status and Adenovirus serostatus [62]. As adenoviral vectors were considered to be the most immunogenic viral vectors available, the HIV-1 vaccine community struggled to understand these results.

After careful analysis of the STEP Study results, a DNA prime/ rAd5 boost vaccine trial utilizing the VRC adenovirus vector was conducted (HVTN 505) [63]. This study utilized a DNA prime that contained plasmids expressing 6 HIV proteins; Gag, Pol and Nef from clade B and Env from clade A, B and C. Study subjects also received an adenoviral vector vaccine, expressing Gag-Pol fusion protein from clade B and Env glycoproteins from clades A, B, and C. It was thought that this vaccine regimen would induce sustained cellular and humoral immune responses against multiple circulating HIV strains. In this study, all subjects were men who have sex with men, at high-risk for HIV acquisition, but were required to be circumcised and have low preexisting Ad5 antibody titers thereby eliminating potential confounders from the STEP study. There were 2500 individuals enrolled at sites across the United States. Once again, the DNA prime/rAd5 boost regimen induced cellular and humoral immune responses, but these were insufficient for protection against HIV acquisition. This study also concluded early when interim analysis demonstrated vaccine futility. Although not statistically significant, there were more HIV-1 infections in the vaccinated group than in the placebo group [63]. It remains unclear why individuals who received an Ad5 HIV vaccine appear to be at increased risk of acquiring HIV-1 infection. Recent data suggests Ad5 vaccination increases the concentration of activated CD4+ T cells in gut mucosa, suggesting that increased HIV infection may be due to the very immune response that the vaccine aims to elicit [64]. The future use of adenoviral vectors in HIV vaccine development will likely proceed with caution if at all.

\section{A door closes... and a window opens}

Canarypox virus (ALVAC) is an avian poxvirus that undergoes an abortive replication cycle in mammalian cells. Multiple constructs expressing different HIV proteins have been tested in search of a HIV-1 vaccine. This vector was capable of inducing antibody and cytotoxic $\mathrm{T}$ cell responses, but these responses were relatively weak and short-lived [65-67]. As adenoviral constructs prompted more sustained responses in early studies, ALVAC vectors were largely abandoned until a team of researchers from the Thai AIDS Vaccine Evaluation Group combined ALVAC with the subunit vaccine, AIDSVAX B/E (which had failed in the Vax003 trial) in a "prime and boost" model of vaccination.

The RV144 trial, as this study is now known, initially strongly discouraged by the scientific community, turned out to be abreakthrough in HIV vaccine development. The study itself was designed as a community-based, randomized trial, examining the effect of HIV vaccination on the general population, not just those at high risk for infection [7]. As a result, over 16,000 individuals were enrolled and over 12,000 completed all study-related visits. When the results were tabulated, this vaccine regimen demonstrated $31 \%$ efficacy in modified intention-to-treat analysis. This study is not without limitations. As critics have noted, the efficacy was highest early on and in those at lowest risk for HIV infection [68]. However, this was the first time a HIV vaccine demonstrated any, albeit limited, efficacy in human trials.

Since 2009, many researchers have sought to understand the protective effect of the ALVAC/AIDSVAX vaccine. It is thought that the study of these correlates of protection may hold the keys to an effective HIV vaccine. Interestingly, the RV144 vaccine did not induce either broadly neutralizing antibodies or cytotoxic CD8+ T cell responses. Instead, the vaccine induced $\mathrm{CD} 4+\mathrm{T}$ cell and antibody-dependent cytotoxicity and weakly neutralizing antibodies [69-72]. Specifically, individuals with higher plasma concentrations of immunoglobulin $G$ (IgG) antibodies specific for the V1V2 loop of gp120 had lower rates of HIV infection, while high levels Env-specific IgA antibodies directly correlated with HIV infection [73]. Additional studies suggested that HIV-1 envelope C1 antibody responses were the dominant antibodydependent cellular cytotoxic response responsible for protection [74]. Recently, other studies have explored host genetic factors that contributed to the protective vaccine effect: for example, vaccine efficacy was higher in individuals with the HLA $A^{\star} 02$ allele in the RV144 trial [75]. Thus, the RV144 trial opened many more windows 
of discovery that may ultimately lead to the development of an effective HIV vaccine (Table 2).

\section{A Way Forward}

In the past decade, advances in research have shown multiple paths forward. These paths are diverse, and include newly identified broadlyneutralizing antibodies and the possible use of monoclonal antibodies. As understanding of HIV-1 infectionincreases, new hope has been placed in older strategies such as gp120 subunit vaccines and less on the use of cytotoxic vaccines although work in this area continues.

\section{Broadly neutralizing antibodies}

The majority of HIV infected individuals will mount a humoral immune response in the weeks to months following HIV-1 infection. This response, however, is usually strain-specific and does not confer immunity but instead drives viral mutation [86,87]. Over time, approximately $10-30 \%$ of people will develop broadly neutralizing antibodies (BNAbs) but only $\sim 1 \%$ will produce antibodies with extensive breadth and potency ("elite neutralizers") [86,88]. This process can take between 2 to 4 years. As a result, most HIV infected persons do not benefit from their neutralizing antibodies, partly due to the presence of viral escape mutants and partly due to waning humoral immune response [86,89]. Recent studies have emphasized the importance of BNAbs in blocking infection by chimeric simian human immunodeficiency virus in non-human primate studies and preventing HIV-1 viral load rebound after cessation of antiretroviral therapy in humans [90-96]. These studies led to an abundance of research into identifying BNAbs with the rationale that these naturally occurring BNAbs could be exploited for vaccine development and provide clues toward immunogen design [97]. Several BNAbs have been identified and are summarized in Table 3. These antibodies target multiple epitopes in HIV envelope proteins, some requiring glycosylation or quaternary structure for neutralization. Recently Pfeifer et al. determined that resistance to BNAbs is associated with coreceptor usage, suggesting the importance of viral tropism to vaccine development [98]. To date, no vaccine has been able to elicit formation of these BNAbs, but considerable research is still ongoing [99]. A recent study suggested that BNAbsmay have a role in immunotherapy of HIV-
1 infection. Barouch et al. showed a single infusion of a cocktail of three BNAbs conferred a significant decline in HIV-1 viral load within 7 days and reduced proviral DNA in peripheral blood, gastrointestinal mucosa and lymph nodes without the development of viral resistance in rhesus macaques [100]. Hence, BNAbs may be important for both preventive and therapeutic strategies and provide a pragmatic way forward.

\section{Nonneutralizing antibodies}

There are aspects of BNAbs that add to their complexity and may explain the difficulty in inducing their expression after vaccination. Sequencing of isolated BNAbs revealed extensive somatic hypermutation and long complementarity determining loops, suggesting a long maturation process is necessary for antibody effectiveness $[86,101,116]$. As a result, some researchers have explored the potential impact of "conventional" antibodies on the HIV epidemic. Viral neutralization is thought to require antibody binding to the envelope trimeric spike, preventing engagement with receptor or co-receptor, or preventing conformational changes required for viral fusion. Non-neutralizing antibodies (NoNAbs) bind to other proteins on surface of HIV virions or infected cells (i.e. envelope monomers or gp41 stumps) via Fab domains and present to antigen-presenting cells or NK cells via $\mathrm{Fc}$ domains, causing viral inhibition through phagocytosis or antibodydependent cellular cytotoxicity (ADCC) [116-119]. Over the years, multiple studies have implicated a role for these NoNAbs in abrogating infection in vitro and in animal models [88]. However, the results of the RV144 trial renewed interest in this field when it was determined that vaccine protection was not due to induction of BNAbs, but rather of NoNAbIgG against V1/V2 and C1 domains of gp120 [73]. Interestingly, researchers observed an inverse relationship between risk of infection and expression of plasma IgA antibodies. In study participants, monoclonal Abs that mediated ADCC were specific for the conserved C1 region in gp120. Vaccine-induced plasma IgA was also specific for the $\mathrm{C} 1$ region and would compete with $\operatorname{IgG}$, thereby preventing IgG-mediated ADCC from occurring and potentially explaining the increased rates of HIV infection in participants with high IgA antibody levels $[120,121]$. Since secretory $\operatorname{IgA}$ antibodies have a significant protective effect in mucosal immunization by binding virions in the lumen and limiting HIV transmission, these findings suggest a dual

\begin{tabular}{|l|l|l|l|l|}
\hline Trial Name & Candidate Vaccine & Location & Population & Outcome \\
\hline Vax 004 & AIDSVAX B/B & USA & MSM, high risk women & No efficacy \\
\hline Vax 003 & AIDSVAX B/E & Thailand & IV drug users & No efficacy \\
\hline HVTN 502 / STEP & MRK Ad5 gag/pol/nef B & $\begin{array}{l}\text { Australia, Caribbean, } \\
\text { the Americas }\end{array}$ & $\begin{array}{l}\text { MSM, high risk men and } \\
\text { women }\end{array}$ & $\begin{array}{l}\text { No protection, transient increased risk. Study } \\
\text { terminated early }\end{array}$ \\
\hline $\begin{array}{l}\text { HVTN 503 / } \\
\text { Phambili }\end{array}$ & MRK Ad5 gag/pol/nef B & South Africa & Men and women & $\begin{array}{l}\text { Study terminated due to STEP trial findings. Post-hoc } \\
\text { analysis indicating increased risk with vaccine }\end{array}$ \\
\hline HVTN 505 & [61,62] & [60,78-81] \\
\hline RV 144 & ALVAC / AIDSVAX B/E & Thailand & $\begin{array}{l}\text { Circumcised men and } \\
\text { MTF transgender }\end{array}$ & $\begin{array}{l}\text { Stopped for futility, participants are being monitored } \\
\text { [63] }\end{array}$ \\
\hline
\end{tabular}

Table 2: Summary of Phase IIb and Phase III HIV Vaccine Trials.

\begin{tabular}{|c|c|c|c|c|c|}
\hline Target Site & Antibodies & $\begin{array}{c}\text { Glycan } \\
\text { Dependent }\end{array}$ & \begin{tabular}{c|} 
Quaternary \\
Structure Dependent
\end{tabular} & Coreceptor association & References \\
\hline gp120 CD4 binding site & b12, NIH45-46, VRC01, PGV04, 3BNC117 & No & No & Unknown & {$[101-104]$} \\
\hline gp120 outer domain & 2G12, PGT 135-137 & Yes & No & Unknown & {$[105,106]$} \\
\hline gp120 V3 & PGT 121-123; PGT 125-128, PGT 130-131 & Yes & No & PGT 128 selects $X 4$ tropism & {$[98,106]$} \\
\hline gp120 V1V2 & PGT 141-145; PG9/PG16; CH01-04 & Yes & Yes & PG9/PG16 : R5 tropic & {$[98,106-108]$} \\
\hline gp41 MPER & 2F5; 4E10; 10E8 & No & No & Unknown & [109-113] \\
\hline gp120:gp41 cleaved trimer & PGT 151-158 & Yes & Yes & & {$[114,115]$} \\
\hline
\end{tabular}

Table 3: Broadly Neutralizing Antibodies against HIV. 
role for IgA based on localization, structure and epitope [116,122]. The RV144 findings have been replicated in a macaque model, again with approximately $30 \%$ protection. Subsequent animal studies showed that NoNAbs with ADCC potential were unable to prevent infection of macaques following high-dose SHIV challenge, but did decrease subsequent viral replication and dissemination [117,123]. Although BNABs may be more effective, considerable evidence suggests there may be a role for NoNAbs in an effective HIV vaccine.

\section{Gp120/gp140}

The HIV envelope protein has long been a target for vaccine design, and yet antibodies against monomeric gp120 have not led to an effective vaccine. One possible explanation is that gp120 exists in a trimeric envelope (Env) spike with 3 gp120 and 3 gp41 proteins. Unfortunately, the instability of this protein has led to significant difficulties in creating synthetic Envtrimers. Significant attention is currently being directed to the envelope spike complex (gp140, lacking the transmembrane domain of gp41), as isolated from HIV infected individuals with BNAbs. In animal studies, gp140 induced higher titers of anti-gp120 specific Abs and neutralizing Abs than monomeric gp120 [124]. In late 2013, researchers announced the creation of a synthetic Envtrimer BG505 SOSIP.664 that induced BNAbs but not non-neutralizing Abs [125]. Subsequently, researchers from the HIV Vaccines Trial Network published the results of a phase IIa study where study participants were vaccinated with a DNA prime and MVA boost that produces noninfectious virus-like particles (VLPs) with Envtrimers on the VLP surface [126]. Although this vaccine regimen induced antibody and $\mathrm{T}$ cell responses, such responses waned within 3 months after completing immunization. In 2013, Baden et al. described a novel HIV vaccine prototype that encoded gp140 in an adenovirus 26 vector (Ad26.ENVA.01). Early studies showed the Ad26 vector was safe and immunogenic, suggesting it may be an acceptable alternative for adenovirus 5 [127]. Recently, additional efforts demonstrated that a single intramuscular injection of Ad26.ENVA.01 elicited both systemic and mucosal immune responses [128]. Although preliminary, these studies reinforce the concept that Envtrimers/gp140 may serve as important immunogens for the next generation of vaccine development.

\section{Cytotoxic T cells}

Major HIV vaccine trials in the past two decades have tested immunogens that induce cytotoxic $\mathrm{T}$ cell responses. Significant progress has been achieved since the first attempt, where a recombinant vaccinia virus vector was used [129]. This vector was not optimal, as it escaped inactivation and caused three deaths. Safer vectors have been used since, such as pox-based, highly attenuated strains such as Vaccinia Ankara, Copenhagen (NYVAC) and Canarypox (ALVAC) [8]. With safer vectors and the prime-boost method used in RV144 as the first vaccine with limited efficacy, there may still be a future for vaccines that induce cell-mediated responses [7]. Replicating viral vectors such as Measles, Vesicular stomatitis virus and Cytomegalovirus (CMV) may hold the key to a sustainable cytotoxic response. A study using rhesus cytomegalovirus (RhCMV) vectors established indefinitely persistent, high-frequency, SIV-specific effector memory T-cell responses at potential sites of SIV replication in rhesus macaques. It was able to control highly pathogenic SIV infection early after mucosal challenge [130]. Halting viral replication at early stages of infection via eliciting cytotoxic responses in mucous membranes may halt acquisition of the virus at this crucial initial stage. Persistent vectors such as CMV may be able to elicit strong and persistent cytotoxic responses [130,131]. Recent evidence also points to the possibility of this approach to clear reservoirs of lentivirus as well [132].

\section{Mosaic and conserved sequence vaccines}

The global strain diversity of HIV requires an effective vaccine to elicit broad neutralizing responses from the host immune system. Since no vaccine has been successful in achieving this goal to date through conventional methods, some researchers developed a novel strategy wherein they use bioinformatics to guide vaccine development. Mosaic vaccines contain several proteins or their corresponding genes and are designed to include the most common $\mathrm{T}$ cell epitopes and those likely involved in escape variants, and exclude rare epitopes, in order to trigger cytotoxic $\mathrm{T}$ cell responses [133]. Conserved sequence vaccines create an immunogen from the highly conserved regions of the HIV consensus proteome, thereby forming a vaccine that would be effective against all HIV viral clades [134]. Both methods show some promise in that they are able to induce $\mathrm{T}$ cell responses in animal models [135137]. Recently, Barouch et al. [138] investigated whether mosaic Env/ Gag/Pol immunogens would protect NHP from repeated intrarectal challenge with heterologous SHIV viruses. They observed robust immune responses in vaccinated monkeys and this correlated with a low rate of SHIV infection following the first intrarectal challenge. However, this protective effect peaked at approximately $90 \%$ and waned with repeated challenges. A significant limitation of this study was that only one SHIV strain was investigated, so it remains unclear whether mosaic vaccines could protect against multiple HIV clades as suggested $[138,139]$

\section{Vectored immunoprophylaxis}

An alternative approach to inducing humoral immunity is to cause expression of BNAbs via vectored immunoprophylaxis (VIP). In this technique, viral vectors deliver genes encoding the BNAbs to cells directly, and the host's immune system then produces the antibodies internally. Animal studies showed that humanized mice injected with adenovirus-associated viral vectors encoding various different BNAbs were protected against intravenous or repeated intravaginal challenges with high doses of HIV $[140,141]$. This technique has only been studied in early animal models, but there is a proof of principle that is worthy of further investigation.

\section{Immune tolerance}

Perhaps the most intriguing vaccine strategy is one that does not require antibody production at all, but rather attempts to trigger tolerance of HIV infection. Since resting CD4+ T cells are resistant to HIV infection, it is thought that a tolerogenic vaccine could prevent new infections from occurring. In 2012, Lu et al. first described using an oral vaccine combination of inactivated SIV and commensal bacteria to induce CD4 T cell unresponsiveness [142]. This vaccine strategy was successful in preventing SIV infection of 15 out of 16 macaques following intrarectal challenge, without triggering antibody or cytotoxic $\mathrm{T}$ cell responses. Instead, protection was due to the presence of MHC$\mathrm{Ib} / \mathrm{E}$-restricted $\mathrm{CD} 8+$ regulatory $\mathrm{T}$ cells that prevented activation of CD4+ T cells. These findings were replicated in a larger study in Chinese macaques, where oral or intravaginal immunization protected the animals from SIV infection via intravenous or intrarectal viral challenge. This protection did not wane after repeated challenge, was effective 48 months after vaccination and was cross protective against other SIV strains [143]. This research group plans on proceeding to phase I human trials soon.

\section{Conclusions}

Finding a safe and effective HIV-1 vaccine remains one of the highest research priorities. A preventive HIV vaccine would curb this devastating 
pandemic and have a significant public health impact. Decades of research have led to new discoveries in the immunopathogenesis of this infection, but have not yet yielded a highly effective vaccine. Recent advances suggest that preventive HIV vaccines are possible, and even likely. The obstacles and challenges to vaccine development and the urgent need for effective HIV prevention strategies have led to the development of a number of prevention approaches beyond the traditional preventive vaccines. These approaches will need to be incorporated into future vaccine trials design since they are already in use and vaccine trials without the use of these methods may pose ethical issues. A future HIV preventive vaccine may target multiple immune pathways and involve strategies such as cytotoxic vaccines, envelope targets and antibodies such as BNAbs or MAbs. Even a vaccine with moderate efficacy would have a major public health impact if combined with a comprehensive prevention package that includes counseling, barrier methods and PrEP. The path in vaccine development to this point has been difficult, and portends a still challenging road ahead, but there has been unmistakable progress, and failure is not an option.

\section{References}

1. WHO (2014) HIVIAIDS - Data and Statistics.

2. Goosby E, Dybul M, Fauci AS, Fu J, Walsh T, et al. (2012) The United States President's Emergency Plan for AIDS Relief: a story of partnerships and smart investments to turn the tide of the global AIDS pandemic. J Acquir Immune Defic Syndr 60 Suppl 3: S51-56.

3. Palen J, El-Sadr W, Phoya A, Imtiaz R, Einterz R, et al. (2012) PEPFAR, health system strengthening, and promoting sustainability and country ownership. $J$ Acquir Immune Defic Syndr 60 Suppl 3: S113-119.

4. Altman LK (1996) Combination Strategy Reinvigorates Search for AIDS Vaccine. The Doctors World, New York Times.

5. Duerr A, Wasserheit JN, Corey $L$ (2006) HIV vaccines: new frontiers in vaccine development. Clin Infect Dis 43: 500-511.

6. Barouch D, Baden L, Dolin R (2010) Vaccines for Human Immunodeficiency Virus-1 Infection. Mand. Douglas, Bennett's Princ. Pract. Infect. Dis., 7th ed. Churchill Livingstone Elsevier, Philadelphia, PA, pp 1887-1895.

7. Rerks-Ngarm S, Pitisuttithum P, Nitayaphan $S$, Kaewkungwal J, Chiu J, et al. (2009) Vaccination with ALVAC and AIDSVAX to prevent HIV-1 infection in Thailand. N Engl J Med 361: 2209-2220.

8. Johnston MI, Fauci AS (2007) An HIV vaccine--evolving concepts. N Engl J Med 356: 2073-2081.

9. Koup RA, Safrit JT, Cao Y Andrews CA, McLeod G, et al (1994) Temporal association of cellular immune responses with the initial control of viremia in primary human immunodeficiency virus type 1 syndrome. J Virol 68: 46504655.

10. Richman DD, Wrin T, Little SJ, Petropoulos CJ (2003) Rapid evolution of the neutralizing antibody response to HIV type 1 infection. Proc Natl Acad Sci U S A 100: 4144-4149.

11. Hütter G, Nowak D, Mossner M, Ganepola S, Müssig A, et al. (2009) Long-term control of HIV by CCR5 Delta32/Delta32 stem-cell transplantation. $\mathrm{N}$ Engl J Med 360: 692-698.

12. Finzi D, Blankson J, Siliciano JD, Margolick JB, Chadwick K, et al. (1999) Latent infection of CD4+ T cells provides a mechanism for lifelong persistence of HIV1 , even in patients on effective combination therapy. Nat Med 5: 512-517.

13. Gallo RC, Sarin PS, Gelmann EP, Robert-Guroff M, Richardson E, et al (1983) Isolation of human T-cell leukemia virus in acquired immune deficiency syndrome (AIDS). Science 220: 865-867.

14. Reitzjr MS, Gallo RC (2010) Human Immunodeficiency Viruses. Mand Douglas, Bennett's Princ. Pract. Infect. Dis., (7th Ed.), Churchill Livingstone Elsevier, Philadelphia, PA, 2323-2335.

15. Taylor BS, Hammer SM (2008) The challenge of HIV-1 subtype diversity. N Engl J Med 359: 1965-1966.

16. Kwong PD, Mascola JR, Nabel GJ (2012) The changing face of HIV vaccine research. J Int AIDS Soc 15: 17407.
17. Burton DR, Desrosiers RC, Doms RW, Koff WC, Kwong PD, et al. (2004) HIV vaccine design and the neutralizing antibody problem. Nat Immunol 5: 233-236.

18. Gamble LJ, Matthews QL (2010) Current progress in the development of a prophylactic vaccine for HIV-1. Drug Des Devel Ther 5: 9-26.

19. Pereira L, Srinivasan P, Smith J (2012) Simian-Human Immunodeficiency Viruses and Their Impact on Non-Human Primate Models for AIDS. Immunodeficiency.

20. Daniel MD, Letvin NL, King NW, Kannagi M, Sehgal PK, et al. (1985) Isolation of T-cell tropic HTLV-III-like retrovirus from macaques. Science 228: 1201-1204.

21. Kestler H, Kodama T, Ringler D, Marthas M, Pedersen N, et al. (1990) Induction of AIDS in rhesus monkeys by molecularly cloned simian immunodeficiency virus. Science 248: 1109-1112.

22. Initiative IAV (2009) New report finds first decline in HIV vaccine R\&D investment in a decade.

23. AVAC, IAVI, UNAIDS (2013) From Research to Reality: Investing in HIV Prevention Research in a Challenging Landscape.

24. Demers KR, Reuter MA, Betts MR (2013) CD8(+) T-cell effector function and transcriptional regulation during HIV pathogenesis. Immunol Rev 254: 190-206.

25. Iwasaki A (2012) Innate immune recognition of HIV-1. Immunity 37: 389-398.

26. Daniel MD, Kirchhoff F, Czajak SC, Sehgal PK, Desrosiers RC (1992) Protective effects of a live attenuated SIV vaccine with a deletion in the nef gene. Science 258: 1938-1941.

27. Baba TW, Liska V, Khimani AH, Ray NB, Dailey PJ, et al. (1999) Live attenuated multiply deleted simian immunodeficiency virus causes AIDS in infant and adult macaques. Nat Med 5: 194-203.

28. Whitney JB, Ruprecht RM (2004) Live attenuated HIV vaccines: pitfalls and prospects. Curr Opin Infect Dis 17: 17-26.

29. Ruprecht RM (1999) Live attenuated AIDS viruses as vaccines: promise or peril? Immunol Rev 170: 135-149.

30. Learmont J, Tindall B, Evans L, Cunningham A, Cunningham P, et al. (1992) Long-term symptomless HIV-1 infection in recipients of blood products from a single donor. Lancet 340: 863-867.

31. Learmont J, Cook L, Dunckley H, Sullivan JS (1995) Update on long-term symptomless HIV type 1 infection in recipients of blood products from a single donor. AIDS Res Hum Retroviruses 11: 1.

32. Salk JE, Krech U, Youngner JS, Bennett BL, Lewis LJ, et al. (1954) Formaldehyde treatment and safety testing of experimental poliomyelitis vaccines. Am J Public Health Nations Health 44: 563-570.

33. Nathanson N, Langmuir Ad (1963) The Cutter Incident. Poliomyelitis Following Formaldehyde- Inactivated Poliovirus Vaccination In The United States During The Spring Of 1955. li. Relationship Of Poliomyelitis To Cutter Vaccine. Am J Hyg 78: 29-60.

34. Kahn JO, Cherng DW, Mayer K, Murray H, Lagakos S (2000) Evaluation of HIV-1 immunogen, an immunologic modifier, administered to patients infected with HIV having 300 to $549 \times 10(6) / L$ CD4 cell counts: A randomized controlled trial. JAMA 284: 2193-2202.

35. Angel JB, Routy JP, Tremblay C, Ayers D, Woods R, et al. (2011) A randomized controlled trial of HIV therapeutic vaccination using ALVAC with or without Remune. AIDS 25: 731-739.

36. Pharmabiz.com (2014) Immune Response's Remune vaccine gets US FDA orphan drug status for paediatric HIV diseases.

37. Belshe RB, Graham BS, Keefer MC, Gorse GJ, Wright P, et al. (1994) Neutralizing antibodies to HIV-1 in seronegative volunteers immunized with recombinant gp120 from the MN strain of HIV-1. NIAID AIDS Vaccine Clinica Trials Network. JAMA 272: 475-480.

38. Kahn JO, Sinangil F, Baenziger J, Murcar N, Wynne D, et al. (1994) Clinica and immunologic responses to human immunodeficiency virus (HIV) type 1SF2 gp120 subunit vaccine combined with MF59 adjuvant with or without muramy tripeptide dipalmitoyl phosphatidylethanolamine in non-HIV-infected human volunteers. J Infect Dis 170: 1288-1291.

39. Dolin R, Graham BS, Greenberg SB, Tacket CO, Belshe RB, et al. (1991) The safety and immunogenicity of a human immunodeficiency virus type 1 (HIV-1) recombinant gp160 candidate vaccine in humans. NIAID AIDS Vaccine Clinical Trials Network. Ann Intern Med 114:119-127. 
40. Moore JP, Cao Y, Qing L, Sattentau QJ, Pyati J, et al. (1995) Primary isolates of human immunodeficiency virus type 1 are relatively resistant to neutralization by monoclonal antibodies to gp 120 , and their neutralization is not predicted by studies with monomeric gp120. J Virol 69:101-119.

41. Mascola JR, Snyder SW, Weislow OS, Belay SM, Belshe RB, et al. (1996) Immunization with envelope subunit vaccine products elicits neutralizing antibodies against laboratory-adapted but not primary isolates of human immunodeficiency virus type 1. The National Institute of Allergy and Infectious Diseases AIDS Vaccine Evaluation Group. J Infect Dis 173: 340-348.

42. McElrath MJ, Corey L, Montefiori D, Wolff M, Schwartz D, et al. (2000) A phase II study of two HIV type 1 envelope vaccines, comparing their immunogenicity in populations at risk for acquiring HIV type 1 infection. AIDS Vaccine Evaluation Group. AIDS Res Hum Retroviruses 16: 907-919.

43. Flynn NM, Forthal DN, Harro CD, Judson FN, Mayer KH, et al. (2005) Placebocontrolled phase 3 trial of a recombinant glycoprotein 120 vaccine to prevent HIV-1 infection. J Infect Dis 191: 654-665.

44. Jones NG, DeCamp A, Gilbert P, Peterson ML, Gurwith M, et al. (2009) AIDSVAX immunization induces HIV-specific CD8+ T-cell responses in highrisk, HIV-negative volunteers who subsequently acquire HIV infection. Vaccine 27: $1136-1140$

45. Pitisuttithum P, Gilbert P, Gurwith M, Heyward W, Martin M, et al. (2006) Randomized, double-blind, placebo-controlled efficacy trial of a bivalent recombinant glycoprotein 120 HIV-1 vaccine among injection drug users in Bangkok, Thailand. J Infect Dis 194:1661-1671.

46. Graham BS, Koup RA, Roederer M, Bailer RT, Enama ME, et al (2006) Phase 1 safety and immunogenicity evaluation of a multiclade HIV-1 DNA candidate vaccine. J Infect Dis 194:1650-1660.

47. Catanzaro AT, Roederer M, Koup RA, Bailer RT, Enama ME, et al. (2007) Phase I clinical evaluation of a six-plasmid multiclade HIV-1 DNA candidate vaccine. Vaccine 25: 4085-4092.

48. Mascola JR, Sambor A, Beaudry K, et al (2005) Neutralizing Antibodies Elicited by Immunization of Monkeys with DNA Plasmids and Recombinant Adenoviral Vectors Expressing Human Immunodeficiency Virus Type 1 Proteins Neutralizing Antibodies Elicited by Immunization of Monkeys with DNA Plasmids and Records. J Virol 79: 771-779.

49. Eller MA, Eller LA, Opollo MS, Ouma BJ, Oballah PO, et al. (2007) Induction of HIV-specific functional immune responses by a multiclade HIV-1 DNA vaccine candidate in healthy Ugandans. Vaccine 25: 7737-7742.

50. Hu SL, Kosowski SG, Dalrymple JM (1986) Expression of AIDS virus envelope gene in recombinant vaccinia viruses. Nature 320: 537-540.

51. Cooney EL, Collier AC, Greenberg PD, Coombs RW, Zarling J, et al. (1991) Safety of and immunological response to a recombinant vaccinia virus vaccine expressing HIV envelope glycoprotein. Lancet 337: 567-572.

52. Hu SL, Fultz PN, McClure HM, Eichberg JW, Thomas EK, et al. (1987) Effect of immunization with a vaccinia-HIV env recombinant on HIV infection of chimpanzees. Nature 328: 721-723.

53. McCormack S, Stöhr W, Barber T, Bart PA, Harari A, et al. (2008) EV02: a Phase I trial to compare the safety and immunogenicity of HIV DNA-C primeNYVAC-C boost to NYVAC-C alone. Vaccine 26: 3162-3174.

54. Harari A, Bart PA, Stöhr W, Tapia G, Garcia M, et al. (2008) An HIV-1 clade C DNA prime, NYVAC boost vaccine regimen induces reliable, polyfunctional, and long-lasting T cell responses. J Exp Med 205: 63-77.

55. Guimarães-Walker A, Mackie N, McCormack S, Hanke T, Schmidt C, et al. (2008) Lessons from IAVI-006, a phase I clinical trial to evaluate the safety and immunogenicity of the PTHr.HIVA DNA and MVA.HIVA vaccines in a primeboost strategy to induce HIV-1 specific T-cell responses in healthy volunteers. Vaccine 26: 6671-6677.

56. Howles S, Guimarães-Walker A, Yang H, Hancock G, di Gleria $\mathrm{K}$, et al. (2010) Vaccination with a modified vaccinia virus Ankara (MVA)-vectored HIV-1 immunogen induces modest vector-specific T cell responses in human subjects. Vaccine 28: 7306-7312.

57. Santra S, Seaman MS, Xu L, Barouch DH, Lord Cl, et al. (2005) Replicationdefective adenovirus serotype 5 vectors elicit durable cellular and humoral immune responses in nonhuman primates. J Virol 79: 6516-6522.

58. Seaman MS, Xu L, Beaudry K, Martin KL, Beddall MH, et al. (2005) Multiclade human immunodeficiency virus type 1 envelope immunogens elicit broad cellular and humoral immunity in rhesus monkeys. J Virol 79: 2956-2963.
59. Priddy FH, Brown D, Kublin J, Monahan K, Wright DP, et al. (2008) Safety and immunogenicity of a replication-incompetent adenovirus type 5 HIV-1 clade B $\mathrm{gag} / \mathrm{pol} / \mathrm{nef}$ vaccine in healthy adults. Clin Infect Dis 46: 1769-1781.

60. Buchbinder SP, Mehrotra DV, Duerr A, Fitzgerald DW, Mogg R, et al. (2008) Efficacy assessment of a cell-mediated immunity HIV-1 vaccine (the Step Study): a double-blind, randomised, placebo-controlled, test-of-concept trial. Lancet 372: 1881-1893.

61. Gray GE, Allen M, Moodie Z, Churchyard G, Bekker LG, et al. (2011) Safety and efficacy of the HVTN 503/Phambili study of a clade-B-based HIV-1 vaccine in South Africa: a double-blind, randomised, placebo-controlled test-of-concept phase 2b study. Lancet Infect Dis 11: 507-515.

62. Gray GE, Moodie Z, Metch B, Gilbert PB, Bekker LG, et al. (2014) Recombinant adenovirus type $5 \mathrm{HIV}$ gag/pol/nef vaccine in South Africa: unblinded, longterm follow-up of the phase 2b HVTN 503/Phambili study. Lancet Infect Dis 14: 388-396.

63. Hammer SM, Sobieszczyk ME, Janes H, Karuna ST, Mulligan MJ, et al. (2013) Efficacy trial of a DNA/rAd5 HIV-1 preventive vaccine. N Engl J Med 369: 20832092.

64. Fauci AS, Marovich MA, Dieffenbach CW, Hunter E, Buchbinder SP (2014) Immunology. Immune activation with HIV vaccines. Science 344: 49-51.

65. Belshe RB, Gorse GJ, Mulligan MJ, Evans TG, Keefer MC, et al. (1998) Induction of immune responses to HIV-1 by canarypox virus (ALVAC) HIV-1 and gp120 SF-2 recombinant vaccines in uninfected volunteers. NIAID AIDS Vaccine Evaluation Group. AIDS 12: 2407-2415.

66. Clements-Mann ML, Weinhold K, Matthews TJ, Graham BS, Gorse GJ, et al. (1998) Immune responses to human immunodeficiency virus (HIV) type 1 induced by canarypox expressing HIV-1MN gp120, HIV-1SF2 recombinant gp120, or both vaccines in seronegative adults. NIAID AIDS Vaccine Evaluation Group. J Infect Dis 177: 1230-1246.

67. Evans TG, Keefer MC, Weinhold KJ, Wolff M, Montefiori D, et al (1999) A canarypox vaccine expressing multiple human immunodeficiency virus type 1 genes given alone or with rgp120 elicits broad and durable CD8+ cytotoxic T lymphocyte responses in seronegative volunteers. J Infect Dis 180: 290-298.

68. Haynes BF, Liao HX, Tomaras GD (2010) Is developing an HIV-1 vaccine possible? Curr Opin HIV AIDS 5: 362-367.

69. McMichael AJ, Haynes BF (2012) Lessons learned from HIV-1 vaccine trials: new priorities and directions. Nat Immunol 13: 423-427.

70. Montefiori DC, Karnasuta C, Huang Y, Ahmed H, Gilbert P, et al. (2012) Magnitude and breadth of the neutralizing antibody response in the RV144 and Vax003 HIV-1 vaccine efficacy trials. J Infect Dis 206: 431-441.

71. Liu P, Yates NL, Shen X, Bonsignori M, Moody MA, et al. (2013) Infectious virion capture by HIV-1 gp120-specific IgG from RV144 vaccinees. J Virol 87 7828-7836.

72. Karasavvas N, Billings E, Rao M, Williams C, Zolla-Pazner S, et al. (2012) The Thai Phase III HIV Type 1 Vaccine trial (RV144) regimen induces antibodies that target conserved regions within the V2 loop of gp120. AIDS Res Hum Retroviruses 28: 1444-1457.

73. Haynes BF, Gilbert PB, McElrath MJ, Zolla-Pazner S, Tomaras GD, et al. (2012) Immune-correlates analysis of an HIV-1 vaccine efficacy trial. N Engl J Med 366: 1275-1286.

74. Pollara J, Bonsignori M, Moody MA, Liu P, Alam SM, et al. (2014) HIV-1 vaccine-induced C1 and V2 Env-specific antibodies synergize for increased antiviral activities. J Virol 88: 7715-7726.

75. Gartland AJ, Li S, McNevin J, Tomaras GD, Gottardo R, et al. (2014) Analysis of $H_{L A A} 02$ association with vaccine efficacy in the RV144 HIV-1 vaccine trial. J Virol 88: 8242-8255.

76. Gilbert PB, Peterson ML, Follmann D, Hudgens MG, Francis DP, et al. (2005) Correlation between immunologic responses to a recombinant glycoprotein 120 vaccine and incidence of HIV-1 infection in a phase 3 HIV- 1 preventive vaccine trial. J Infect Dis 191: 666-677.

77. Gilbert PB, Ackers ML, Berman PW, Francis DP, Popovic V, et al. (2005) HIV-1 virologic and immunologic progression and initiation of antiretroviral therapy among HIV-1-infected subjects in a trial of the efficacy of recombinant glycoprotein 120 vaccine. J Infect Dis 192: 974-983.

78. McEIrath MJ, De Rosa SC, Moodie Z, Dubey S, Kierstead L, et al. (2008) HIV- 
Citation: Barry SM, Mena Lora AJ, Novak RM (2014) Trial, Error, and Breakthrough: A Review of HIV Vaccine Development. J AIDS Clin Res 5: 359. doi:10.4172/2155-6113.1000359

1 vaccine-induced immunity in the test-of-concept Step Study: a case-cohort analysis. Lancet 372: 1894-1905.

79. Duerr A, Huang Y, Buchbinder S, Coombs RW, Sanchez J, et al. (2012) Extended follow-up confirms early vaccine-enhanced risk of HIV acquisition and demonstrates waning effect over time among participants in a randomized trial of recombinant adenovirus HIV vaccine (Step Study). J Infect Dis 206: 258-266.

80. Koblin BA, Mayer KH, Noonan E, Wang C, Marmor M, et al. (2012) Sexual risk behaviors, circumcision status, and preexisting immunity to adenovirus type 5 among men who have sex with men participating in a randomized HIV-1 vaccine efficacy trial: step study. J Acquir Immune Defic Syndr 60: 405-413.

81. Cheng C, Wang L, Gall JG, Nason M, Schwartz RM, et al. (2012) Decreased pre-existing Ad5 capsid and Ad35 neutralizing antibodies increase HIV-1 infection risk in the Step trial independent of vaccination. PLoS One 7: e33969.

82. de Souza MS, Ratto-Kim S, Chuenarom W, Schuetz A, Chantakulkij S, et al. (2012) The Thai phase III trial (RV144) vaccine regimen induces T cell responses that preferentially target epitopes within the V2 region of HIV-1 envelope. J Immunol 188: 5166-5176.

83. Zolla-Pazner S, deCamp AC, Cardozo T, Karasavvas N, Gottardo R, et al. (2013) Analysis of V2 antibody responses induced in vaccinees in the ALVAC/ AIDSVAX HIV-1 vaccine efficacy trial. PLoS One 8: e53629.

84. Rolland M, Edlefsen PT, Larsen BB, Tovanabutra S, Sanders-Buell E, et al (2012) Increased HIV-1 vaccine efficacy against viruses with genetic signatures in Env V2. Nature 490: 417-420.

85. Robb ML, Rerks-Ngarm S, Nitayaphan S, Pitisuttithum P, Kaewkungwal J, et al. (2012) Risk behaviour and time as covariates for efficacy of the HIV vaccine regimen ALVAC-HIV (VCP1521) and AIDSVAX B/E: a post-hoc analysis of the Thai phase 3 efficacy trial RV 144. Lancet Infect Dis 12: 531-537.

86. van Gils MJ, Sanders RW (2013) Broadly neutralizing antibodies against HIV-1: templates for a vaccine. Virology 435: 46-56.

87. Girard MP, Picot V, Longuet C, Nabel GJ (2013) Report of the Cent Gardes HIV Vaccine Conference: The B-cell Response to HIV. Part 1: Broadly Neutralizing Antibodies Fondation Mérieux Conference Center, Veyrier du Lac, France, 5-7 November 2012. Vaccine 31: 2979-2983.

88. Zolla-Pazner S (2014) A critical question for HIV vaccine development: which antibodies to induce? Science 345: 167-168.

89. Mikell I, Sather DN, Kalams SA, Altfeld M, Alter G, et al. (2011) Characteristics of the earliest cross-neutralizing antibody response to HIV-1. PLoS Pathog 7: e1001251.

90. Baba TW, Liska V, Hofmann-Lehmann R, Vlasak J, Xu W, et al. (2000) Human neutralizing monoclonal antibodies of the IgG1 subtype protect against mucosal simian-human immunodeficiency virus infection. Nat Med 6: 200-206.

91. Hessell AJ, Rakasz EG, Poignard P, Hangartner L, Landucci G, et al. (2009) Broadly neutralizing human anti-HIV antibody $2 \mathrm{G} 12$ is effective in protection against mucosal SHIV challenge even at low serum neutralizing titers. PLoS Pathog 5: e1000433.

92. Hessell AJ, Poignard P, Hunter M, Hangartner L, Tehrani DM, et al. (2009) Effective, low-titer antibody protection against low-dose repeated mucosal SHIV challenge in macaques. Nat Med 15: 951-954.

93. Mascola JR, Lewis MG, Stiegler G, VanCott TC, Katinger H, et al. (1999) Protection of Macaques against Pathogenic Simian / Human Immunodeficiency Virus 89 . 6PD by Passive Transfer of Neutralizing Antibodies Protection of Macaques against Pathogenic Simian / Human Immunodeficiency Virus 89. 6PD by Passive Transfer of Neutral. J Virol 73: 4009-4018.

94. Parren PWHI, Marx PA, Hessell AJ, Luckay A, Harouse J, et al. (2001) Antibody Protects Macaques against Vaginal Challenge with a Pathogenic R5 Simian / Human Immunodeficiency Virus at Serum Levels Giving Complete Neutralization In Vitro Antibody Protects Macaques against Vaginal Challenge with a Pathogenic R5 Simian / Huma. J Virol 75: 8340-8347.

95. Shibata R, Igarashi T, Haigwood N, Buckler-White a, Ogert R, et al. (1999) Neutralizing antibody directed against the HIV-1 envelope glycoprotein can completely block HIV-1/SIV chimeric virus infections of macaque monkeys. Nat Med 5: 204-210.

96. Trkola A, Kuster H, Rusert P, Joos B, Fischer M, et al. (2005) Delay of HIV1 rebound after cessation of antiretroviral therapy through passive transfer of human neutralizing antibodies. Nat Med 11: 615-622.
97. Koff WC (2012) HIV vaccine development: challenges and opportunities towards solving the HIV vaccine-neutralizing antibody problem. Vaccine 30 : 4310-4315.

98. Pfeifer N, Walter H, Lengauer T (2014) Association Between HIV-1 Coreceptor Usage and Resistance to Broadly Neutralizing Antibodies. J Acquir Immune Defic Syndr 67: 107-112.

99. Baden LR, Dolin R (2012) The road to an effective HIV vaccine. N Engl J Med 366: 1343-1344.

100. Barouch DH, Whitney JB, Moldt B, Klein F, Oliveira TY, et al. (2013) Therapeutic efficacy of potent neutralizing HIV-1-specific monoclonal antibodies in SHIVinfected rhesus monkeys. Nature 503: 224-228.

101. Scheid JF, Mouquet H, Ueberheide B, Diskin R, Klein F, et al. (2011) Sequence and structural convergence of broad and potent HIV antibodies that mimic CD4 binding. Science 333: 1633-1637.

102.Zhou T, Xu L, Dey B, Hessell AJ, Van Ryk D, et al. (2007) Structural definition of a conserved neutralization epitope on HIV-1 gp120. Nature 445: 732-737.

103.Zhou T, Georgiev I, Wu X, Yang ZY, Dai K, et al. (2010) Structural basis for broad and potent neutralization of HIV-1 by antibody VRC01. Science 329 : 811-817.

104. Wu X, Yang ZY, Li Y, Hogerkorp CM, Schief WR, et al. (2010) Rational design of envelope identifies broadly neutralizing human monoclonal antibodies to HIV-1. Science 329: 856-861.

105. Trkola A, Purtscher M, Muster T, Ballaun C, Buchacher A, et al. (1996) Human monoclonal antibody $2 \mathrm{G} 12$ defines a distinctive neutralization epitope on the gp120 glycoprotein of human immunodeficiency virus type 1. J Virol 70: 11001108

106. Walker LM, Huber M, Doores KJ, Falkowska E, Pejchal R, et al. (2011) Broad neutralization coverage of HIV by multiple highly potent antibodies. Nature 477: 466-470.

107. Walker LM, Phogat SK, Chan-Hui PY, Wagner D, Phung P, et al. (2009) Broad and potent neutralizing antibodies from an African donor reveal a new HIV-1 vaccine target. Science 326: 285-289.

108. Bonsignori M, Hwang KK, Chen X, Tsao CY, Morris L, et al. (2011) Analysis of a clonal lineage of HIV-1 envelope V2/V3 conformational epitope-specific broadly neutralizing antibodies and their inferred unmutated common ancestors. J Virol 85: 9998-10009.

109. Muster T, Steindl F, Purtscher M, Trkola A, Klima A, et al. (1993) A conserved neutralizing epitope on gp41 of human immunodeficiency virus type 1 . J Virol 67: 6642-6647.

110. Zwick MB, Labrijn AF, Wang M, Spenlehauer C, Saphire EO, et al. (2001) Broadly neutralizing antibodies targeted to the membrane-proximal external region of human immunodeficiency virus type 1 glycoprotein gp41. J Virol 75 10892-10905.

111. Huang J, Ofek G, Laub L, Louder MK, Doria-Rose NA, et al. (2012) Broad and potent neutralization of HIV-1 by a gp41-specific human antibody. Nature 491: 406-412.

112. Cardoso RM, Zwick MB, Stanfield RL, Kunert R, Binley JM, et al. (2005) Broadly neutralizing anti-HIV antibody $4 \mathrm{E} 10$ recognizes a helical conformation of a highly conserved fusion-associated motif in gp41. Immunity 22: 163-173.

113. Ofek G, Tang M, Sambor A, Katinger H, Mascola JR, et al. (2004) Structure and mechanistic analysis of the anti-human immunodeficiency virus type 1 antibody 2F5 in complex with its gp41 epitope. J Virol 78: 10724-10737.

114. Blattner C, Lee JH, Sliepen K, Derking R, Falkowska E, et al. (2014) Structura delineation of a quaternary, cleavage-dependent epitope at the gp41-gp120 interface on intact HIV-1 Env trimers. Immunity 40: 669-680.

115. Falkowska E, Le KM, Ramos A, Doores KJ, Lee JH, et al. (2014) Broadly neutralizing HIV antibodies define a glycan-dependent epitope on the prefusion conformation of gp41 on cleaved envelope trimers. Immunity 40: 657-668.

116. Su B, Moog C (2014) Which Antibody Functions are Important for an HIV Vaccine? Front Immunol 5: 289.

117. Moog C, Dereuddre-Bosquet N, Teillaud JL, Biedma ME, Holl V, et al. (2014) Protective effect of vaginal application of neutralizing and nonneutralizing inhibitory antibodies against vaginal SHIV challenge in macaques. Mucosa Immunol 7: 46-56 
Citation: Barry SM, Mena Lora AJ, Novak RM (2014) Trial, Error, and Breakthrough: A Review of HIV Vaccine Development. J AIDS Clin Res 5: 359. doi:10.4172/2155-6113.1000359

118. Holl V, Peressin M, Moog C (2009) Antibody-Mediated Fcî ${ }^{3}$ ReceptorBased Mechanisms of HIV Inhibition: Recent Findings and New Vaccination Strategies. Viruses 1: 1265-1294.

119. Holl V, Peressin M, Decoville T, Schmidt S, Zolla-Pazner S, et al. (2006) Nonneutralizing antibodies are able to inhibit human immunodeficiency virus type 1 replication in macrophages and immature dendritic cells. J Virol 80: 6177-6181.

120. Tomaras GD, Ferrari G, Shen X, Alam SM, Liao HX, et al. (2013) Vaccineinduced plasma IgA specific for the $\mathrm{C} 1$ region of the HIV-1 envelope blocks binding and effector function of IgG. Proc Natl Acad Sci U S A 110: 9019-9024.

121. Girard MP, Picot V, Longuet C, Nabel GJ (2013) Report of the Cent Gardes HIV Vaccine Conference: The B-cell response to HIV. Part 2: Non-neutralizing antibodies: Fondation Mérieux Conference Center, Veyrier du Lac, France 5-7 November 2012. Vaccine 31: 2984-2987.

122. Watkins JD, Sholukh AM, Mukhtar MM, Siddappa NB, Lakhashe SK, et al. (2013) Anti-HIV IgA isotypes: differential virion capture and inhibition of transcytosis are linked to prevention of mucosal R5 SHIV transmission. AIDS 27: F13-20.

123. Burton DR, Hessell AJ, Keele BF, Klasse PJ, Ketas TA, et al. (2011) Limited or no protection by weakly or nonneutralizing antibodies against vaginal SHIV challenge of macaques compared with a strongly neutralizing antibody. Proc Natl Acad Sci U S A 108:11181-11186.

124. Heyndrickx L, Stewart-Jones G, Jansson M, Schuitemaker H, Bowles E, et al. (2013) Selected HIV-1 Env trimeric formulations act as potent immunogens in a rabbit vaccination model. PLoS One 8: e74552.

125. Sanders RW, Derking R, Cupo A, Julien JP, Yasmeen A, et al. (2013) A nextgeneration cleaved, soluble HIV-1 Env Trimer, BG505 SOSIP.664 gp140, expresses multiple epitopes for broadly neutralizing but not non-neutralizing antibodies. PLoS Pathog 9: e1003618.

126. Goepfert PA, Elizaga ML, Seaton K, Tomaras GD, Montefiori DC, et al. (2014) Specificity and 6-month durability of immune responses induced by DNA and recombinant modified vaccinia Ankara vaccines expressing HIV-1 virus-like particles. J Infect Dis 210: 99-110.

127. Baden LR, Walsh SR, Seaman MS, Tucker RP, Krause KH, et al. (2013) First-in-human evaluation of the safety and immunogenicity of a recombinant adenovirus serotype 26 HIV-1 Env vaccine (IPCAVD 001). J Infect Dis 207: 240-247.

128. Baden LR, Liu J, Li H, Johnson JA, Walsh SR, et al. (2014) Induction of HIV1-specific mucosal immune responses following intramuscular recombinant adenovirus serotype $26 \mathrm{HIV}-1$ vaccination of humans. J Infect Dis .

129. Picard O, Giral P, Defer MC, Fouchard M, Morel M, et al. (1990) AIDS vaccine therapy: phase I trial. Lancet 336: 179.

130. Hansen SG, Ford JC, Lewis MS, Ventura AB, Hughes CM, et al. (2011)
Profound early control of highly pathogenic SIV by an effector memory T-cell vaccine. Nature 473: 523-527.

131. Hansen SG, Vieville C, Whizin N, Coyne-Johnson L, Siess DC, et al. (2009) Effector memory $T$ cell responses are associated with protection of rhesus monkeys from mucosal simian immunodeficiency virus challenge. Nat Med 15: 293-299.

132. Hansen SG, Piatak M Jr, Ventura AB, Hughes CM, Gilbride RM, et al. (2013) Immune clearance of highly pathogenic SIV infection. Nature 502: 100-104.

133. Fischer W, Perkins S, Theiler J, Bhattacharya T, Yusim K, et al. (2007) Polyvalent vaccines for optimal coverage of potential T-cell epitopes in global HIV-1 variants. Nat Med 13: 100-106

134. Létourneau S, Im EJ, Mashishi T, Brereton C, Bridgeman A, et al. (2007) Design and pre-clinical evaluation of a universal HIV-1 vaccine. PLoS One 2: e984.

135. Stephenson KE, SanMiguel A, Simmons NL, Smith K, Lewis MG, et al. (2012) Full-length HIV-1 immunogens induce greater magnitude and comparable breadth of $\mathrm{T}$ lymphocyte responses to conserved HIV-1 regions compared with conserved-region-only HIV-1 immunogens in rhesus monkeys. J Virol 86: 11434-11440.

136. Santra S, Liao HX, Zhang R, Muldoon M, Watson S, et al. (2010) Mosaic vaccines elicit CD8+ $T$ lymphocyte responses that confer enhanced immune coverage of diverse HIV strains in monkeys. Nat Med 16: 324-328.

137. Barouch DH, O'Brien KL, Simmons NL, King SL, Abbink P, et al. (2010) Mosaic HIV-1 vaccines expand the breadth and depth of cellular immune responses in rhesus monkeys. Nat Med 16: 319-323.

138. Barouch DH, Stephenson KE, Borducchi EN, Smith K, Stanley K, et al. (2013) Protective efficacy of a global HIV-1 mosaic vaccine against heterologous SHIV challenges in rhesus monkeys. Cell 155: 531-539.

139. Palesch D, Kirchhoff F (2013) First steps toward a globally effective HIVIAIDS vaccine. Cell 155: 495-497.

140. Balazs AB, Ouyang Y, Hong CM, Chen J, Nguyen SM, et al. (2014) Vectored immunoprophylaxis protects humanized mice from mucosal HIV transmission. Nat Med 20: 296-300

141.Balazs AB, Chen J, Hong CM, Rao DS, Yang L, et al. (2011) Antibody-based protection against HIV infection by vectored immunoprophylaxis. Nature 481 $81-84$

142. Lu W, Chen S, Lai C, Guo W, Fu L, et al. (2012) Induction of CD8+ regulatory T cells protects macaques against SIV challenge. Cell Rep 2: 1736-1746.

143. Andrieu JM, Chen S, Lai C, Guo W, Lu W (2014) Mucosal SIV Vaccines Comprising Inactivated Virus Particles and Bacterial Adjuvants Induce CD8(+) T-Regulatory Cells that Suppress SIV-Positive CD4(+) T-Cell Activation and Prevent SIV Infection in the Macaque Model. Front Immunol 5: 297. 